\title{
Common volume coherent and incoherent scatter radar observations of mid-latitude sporadic E-layers and QP echoes
}

\author{
D. L. Hysell ${ }^{1}$, M. F. Larsen ${ }^{2}$, and Q. H. Zhou ${ }^{3}$ \\ ${ }^{1}$ Earth and Atmospheric Sciences, Cornell University, Ithaca, New York, USA \\ ${ }^{2}$ Department of Physics, Clemson University, Clemson, South Carolina, USA \\ ${ }^{3}$ Manufacturing and Mechanical Engineering Department, Miami University, Oxford, Ohio, USA
}

Received: 12 August 2003 - Revised: 13 October 2003 - Accepted: 20 November 2003 - Published: 23 September 2004

Part of Special Issue "Equatorial and low latitude aeronomy"

\begin{abstract}
Common-volume observations of sporadic Elayers made on 14-15 June 2002 with the Arecibo incoherent scatter radar and a $30 \mathrm{MHz}$ coherent scatter radar imager located on St. Croix are described. Operating in dualbeam mode, the Arecibo radar detected a slowly descending sporadic E-layer accompanied by a series of dense E-region plasma clouds at a time when the coherent scatter radar was detecting quasi-periodic (QP) echoes. Using coherent radar imaging, we collocate the sources of the coherent scatter with the plasma clouds observed by Arecibo. In addition to patchy, polarized scattering regions drifting through the radar illuminated volume, which have been observed in previous imaging experiments, the $30 \mathrm{MHz}$ radar also detected large-scale electrostatic waves in the E-region over Puerto Rico, with a wavelength of about $30 \mathrm{~km}$ and a period of about $10 \mathrm{~min}$, propagating to the southwest. Both the intensity and the Doppler shifts of the coherent echoes were modulated by the wave.
\end{abstract}

Key words. Ionosphere (mid-latitude ionosphere; plasma waves and instabilities) - Radio science (interterometry)

\section{Introduction}

The discovery of quasi-periodic (QP) echoes by Yamamoto et al. $(1991,1992)$ over a decade ago inspired renewed investigations of the electrodynamics and plasma physics of the mid-latitude E-region ionosphere that continue to the present. The small-scale plasma irregularities that give rise to the coherent radar echoes indicate that the plasma in the region is unstable. While a number of theories have been presented in the intervening years, consensus regarding the particular plasma instability at work is elusive. A gradient drift instability similar to the one occurring in the equatorial electrojet is widely considered the most likely candidate. How-

Correspondence to: D. L. Hysell

(daveh@geology.cornell.edu) ever, finite parallel gradient scale length effects at middle latitudes are thought to stabilize gradient drift instabilities (Woodman et al., 1991), at least at large scales. While Seyler et al. (2004) recently showed with a nonlocal analysis that intermediate-scale gradient drift instabilities with finite parallel wave-numbers may form in uniform sporadic E-layers at mid latitudes, their theory does not account for the quasiperiodicity of the radar echoes and, therefore, does not by itself offer a complete explanation of the phenomenon.

Several investigators point out that sporadic E-layers can be unstable to large-or intermediate-scale gradient drift waves, if they have the proper configuration and also appeal to the configuration to explain the quasi-periodicity of the echoes. Woodman et al. (1991) described how finite parallel gradient scale length effects are mitigated when sporadic E-layers are deeply modulated or tilted so as to be aligned with the geomagnetic field. Multiple tilted layers, deformed by internal gravity waves, would be unstable and would also tend to give rise to periodic echoes as they propagate through the scattering volume. Tsunoda et al. (1994) also appealed to gravity waves to induce deep altitude modulations in otherwise planar sporadic E-layers. Because of the altitude dependence of the plasma mobilities, such modulated layers imply the existence of horizontal gradients in the field line integrated conductivities and of induced polarization electric fields that would make them unstable to large-scale gradient drift waves. Quasi-periodicity in this case again follows from gravity wave induced layer modulation.

Maruyama et al. (2000) stressed the morphological similarity between QP echoes and quasi-periodic radio scintillations (QPS), thought to be caused by localized density enhancements or clouds in planar sporadic E-layers. They associated QP echoes with the passage of these density enhancements through the radar scattering volume. Multiple, drifting clouds would give rise to quasi-periodic echoes. However, the enhancements in question are usually taken to be vertically compact. In order to explain how individual QP echoes could arise from a broad span of altitudes, inferred on the basis of radar range-time-intensity (RTI) diagrams to 
be up to $30 \mathrm{~km}$ in extent, Maruyama et al. (2000) proposed that the polarization electric fields in the clouds map along magnetic field lines, and perturb and structure ambient sporadic E-layers at other altitudes. Coherent radar backscatter then originates from the ambient layers. Multiple sporadic Elayers at extreme altitudes are, therefore, thought to be essential. Ogawa et al. (2002) also argue that high density plasma clouds are the ultimate source of QP echoes. Since sporadic E-layers are mainly observed between $90-120 \mathrm{~km}$ altitude (Whitehead, 1989), the QP echoes, often interpreted as coming from a much wider span of altitudes up to $130 \mathrm{~km}$, are thought to come from field-aligned irregularities on the same field lines as the plasma clouds but greatly extended along $\mathbf{B}$. Yokoyama et al. (2003) recently presented numerical simulations suggesting that polarized E-region plasma clouds can induce drastic perturbations in the density and electric field in the plasma lying above them on common field lines.

QP echoes were first associated with patchy or cloud-like sporadic E-layers by Larsen (2000), who further argued that the clouds were generated by neutral shear instabilities. Hysell et al. (2002b) showed that the sources of QP echoes are spatially localized scattering regions that appear to correspond to the polarized, drifting E-region plasma clouds proposed by Larsen (2000). Furthermore, they challenged the conventional means of assigning altitudes to QP echoes and argued on the basis of interferometric measurements that the source regions in question are actually vertically compact, inhabit altitudes between about $95-120 \mathrm{~km}$, and maintain altitude over time as they drift through the scattering volume. Backscatter through a broad antenna main beam or its sidelobes, refraction, and the finite magnetic aspect sensitivity and high dynamic range of the small-scale scattering irregularities involved can explain how the irregularities remain visible to a coherent scatter radar over broad range and time intervals.

In this paper we report on the first common volume observations of mid-latitude sporadic E-layers and QP echoes made, respectively, by the Arecibo $430 \mathrm{MHz}$ incoherent scatter radar and a $30 \mathrm{MHz}$ coherent scatter radar imager located on St. Croix, USVI. Data from these radars allow us to unambiguously collocate and associate meter-scale field-aligned irregularities with the large-scale sporadic E-layer structures they inhabit. The experiments allow us to address longstanding questions regarding the altitude of the irregularities, their position with respect to the ionization layers, the morphology of the layers themselves, and hence the nature of the instability at work.

\section{Experiment description}

In June and July of 2002, a portable $30 \mathrm{MHz}$ radar was deployed on the island of St. Croix, U. S. Virgin Islands, to observe coherent scatter from plasma irregularities in sporadic E-layers situated over Puerto Rico. The objective was to probe the same volume as the Arecibo $430 \mathrm{MHz}$ radar which would simultaneously receive incoherent scatter from the sporadic E-layers. The experiment provided a means of collocating the meter-scale irregularities responsible for coherent scatter with gross features in the ionization. Such information is necessary for validating the various theories that have been put forth to explain quasi-periodic and other echo types and for positively identifying the plasma processes at work.

The Arecibo $430 \mathrm{MHz}$ radar has range resolution as fine as $150 \mathrm{~m}$, high resolution in the direction transverse to the radar beam by virtue of the antenna's 10' half power full beamwidth, and is sufficiently sensitive to measure E-layer electron densities accurately with an incoherent integration time of a few seconds. However, the Arecibo data are inherently ambiguous in that time variations they exhibit may be due either to time variations in the layer, or to movement of the layer through the radar beam, which is itself in motion. Furthermore, beam swinging effectively produces cuts through features in the ionization which fall short of a complete volume rendering. Finally, Arecibo cannot detect coherent scatter and gives no indication of field-aligned irregularities (FAIs) and the stability of the layer.

The spatial resolution of the $30 \mathrm{MHz}$ radar is coarse by comparison to Arecibo. However, with the application of inbeam or aperture synthesis imaging techniques, we can derive from the $30 \mathrm{MHz}$ data true three-dimensional representations of the coherent scatter in the radar-illuminated volume. The images do not suffer from the space-time ambiguities inherent in conventional radar data sets and provide a context for interpreting the Arecibo data. Since the $30 \mathrm{MHz}$ radar has a broad beam, it always illuminates whatever E-region volume is being probed by Arecibo. While the aspect sensitivity of echoes from field-aligned irregularities restricts the region of space probed by the $30 \mathrm{MHz}$ radar, refraction due to sporadic E-layer ionization nevertheless makes it possible to detect possible coherent scatter from most of the sporadic E-layer structures visible to Arecibo.

\subsection{Arecibo radar}

During the June 14-15 experiments described in this paper, Arecibo was operated in dual-beam mode, whereby radiation was emitted and received from both the Gregorian and line feed systems simultaneously. Transmitter power was split between the two feeds, and separate receivers were connected to each. The sensitivity of the two systems was comparable. The feeds are separated in azimuth by $180^{\circ}$, and the zenith angle for both was $15^{\circ}$. Azimuth swinging took place, with the line feed azimuth varying from $0^{\circ}$ to $360^{\circ}$ and back to $0^{\circ}$ at a uniform rate and with a period of slightly less than $1 \mathrm{~h}$.

Three different radar modes were interleaved during the experiments. These were a 13 baud Barker code mode for measuring E- and F-region power profiles, a 200 baud coded long pulse mode for measuring E-region power and autocorrelation functions, and a comparatively low-resolution sevenfrequency mode which measures power and autocorrelation functions in the F-region (Sulzer, 1986). The sampling width 


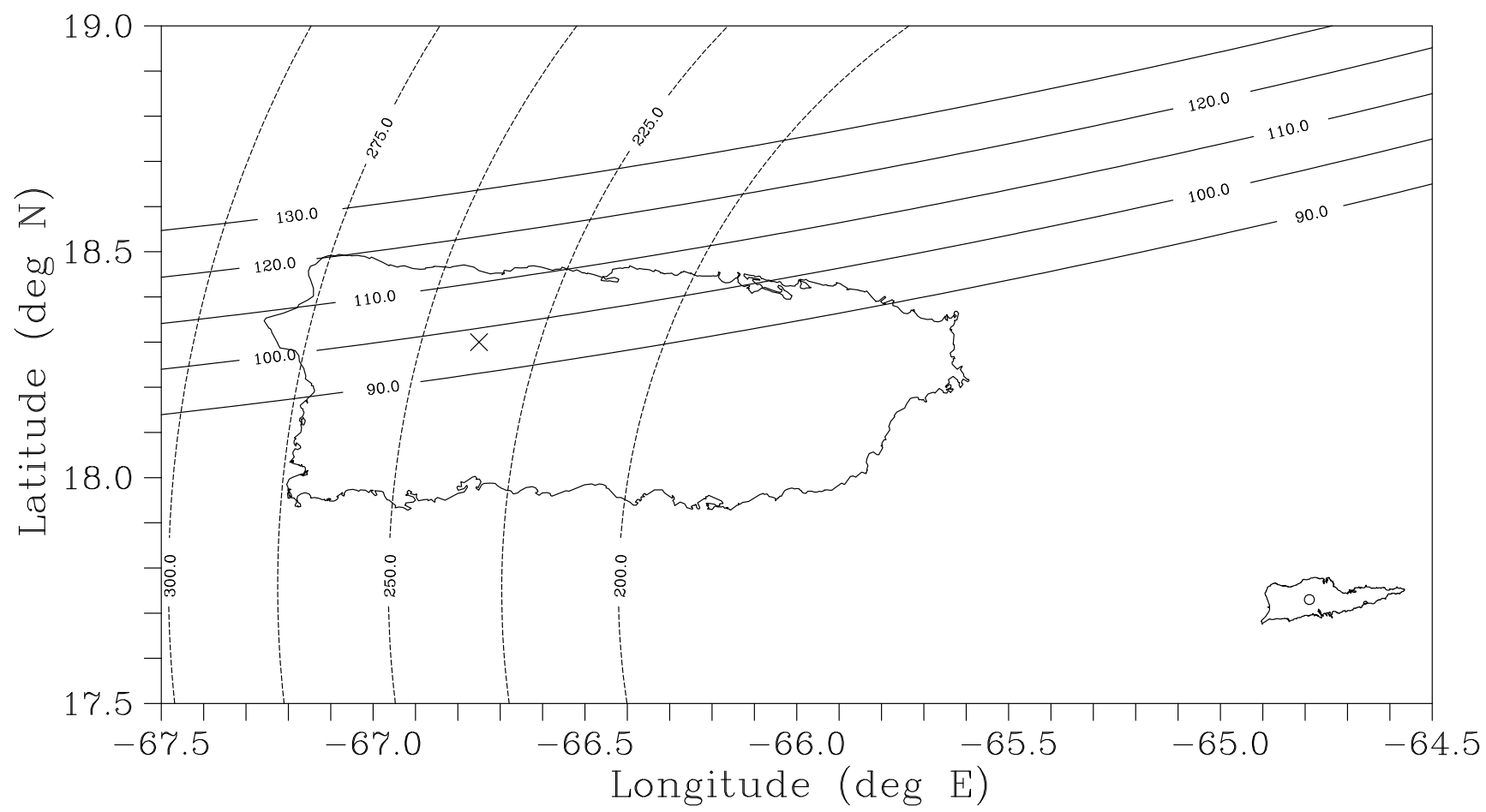

Fig. 1. Map illustrating the geometry of the common-volume radar experiments. An "x" and an "o" mark the locations of the Arecibo and the $30 \mathrm{MHz}$ radars, respectively. Concentric dashed circles indicate the distance from the radar on St. Croix to a point on the circle at $100 \mathrm{~km}$ altitude. Horizontal curves represent the locus of perpendicularity from St. Croix at different altitudes.

for the Barker code and coded long pulse modes was $300 \mathrm{~m}$, although the transmitted baud length of the former was $4 \mu \mathrm{s}$, effectively limiting the range resolution to $600 \mathrm{~m}$ for that mode. (The baud length for the coded long pulse was $2 \mu \mathrm{s}$.) The duty cycle of the experiment was such that $30 \mathrm{~s}$ of each minute were devoted to the coded long pulse mode and $10 \mathrm{~s}$ to the Barker code mode. These data have been processed using a $10 \mathrm{~s}$ incoherent integration time. When plotting the data here, gaps in time are filled by interpolation.

\subsection{Coherent scatter radar imager}

The $30 \mathrm{MHz}$ radar is a portable coherent scatter radar interferometer that has been used to observe QP echoes from Clemson, South Carolina, starting in the summer of 1999 but which was relocated to the National Guard base on St. Croix for the summer 2002 experiments. A description of the radar system hardware can be found in Hysell et al. (2002b). The solid-state transmitter has a peak power of $8 \mathrm{~kW}$ and transmits through an array of 85 -element Yagi-Uda antennas with a combined half power full beamwidth of $10^{\circ}$. For these experiments, the radar transmitted a 28 baud binary phase code with a baud length of $6.67 \mu$ s and a pulse repetition frequency of $250 \mathrm{~Hz}$. Matched filter detection and sampling provided a range resolution of $1 \mathrm{~km}$. The signal-to-noise ratio for sporadic E-layer backscatter for this configuration sometimes exceeded $30 \mathrm{~dB}$. Typical incoherent integrations times for the data are 3 to $6 \mathrm{~s}$.
Figure 1 shows the geometry of the common-volume radar experiments. The main beam of the $30 \mathrm{MHz}$ radar was directed at an azimuth angle of $283^{\circ}$ geographic, $5^{\circ}$ south of the bearing toward Arecibo and in the direction of the most distant E-region field-aligned irregularity backscatter anticipated. The E-region echoes detected by the radar arrived in ranges between 180 and $350 \mathrm{~km}$. For comparison, the range from St. Croix to the E-region directly over Arecibo is about $240 \mathrm{~km}$

This $30 \mathrm{MHz}$ radar differs from more conventional systems in its use of interferometry with multiple baselines to construct true images of the radar targets illuminated by the transmitting antenna beam. Interferometric imaging was implemented first at Jicamarca by Kudeki and Sürücü (1991) and was analyzed in detail subsequently by Woodman (1997). It is well known that interferometry using a single antenna baseline yields two moments of the radio brightness distribution, the distribution of received power versus bearing (Farley et al., 1981). Interferometry with multiple baselines yields multiple moments, and the totality of these moments can be inverted to reconstruct the brightness distribution versus azimuth and zenith angle. The inversion essentially amounts to performing a Fourier transform of the interferometry cross spectra (Thompson, 1986). However, since the cross-spectra are inevitably incompletely sampled due to the limited number of interferometry baselines available, and because of the presence of statistical fluctuations in the data, the inversion must generally be performed us- 

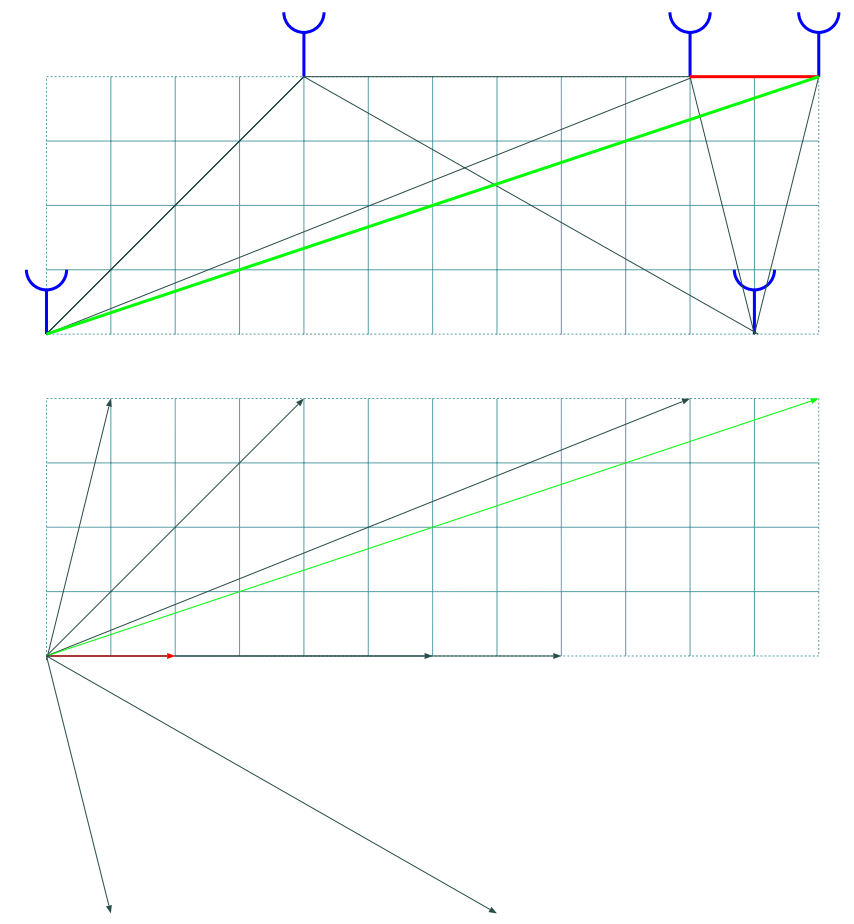

Fig. 2. Representation of the $30 \mathrm{MHz}$ radar interferometry antenna array. (Top panel) Physical locations of the phase centers of the antenna groups used for reception. Up in this figure is in the direction of the main beam of the transmitting antennas. Grid lines are spaced by $5 / 4$ wavelengths. (Bottom panel) Representations of the nine corresponding antenna baselines available for interferometry. These lines are the same as the nine lines drawn above, displaced so as to have a common origin. The shortest and longest baselines are highlighted in red and green, respectively, for emphasis.

ing statistical inverse methods to achieve satisfactory results nearly free of artifacts (Ables, 1974; Jaynes, 1982). For our imaging work, we have employed the MAXent algorithm pioneered for applications in radio astronomy (see, for example, Wilczek and Drapatz, 1985). This is considered a "superresolution" method since there resolution of the images it produces is not limited by the Nyquist sampling theorem. Our problem differs from that in radio astronomy mainly in that radar range gating adds the third dimension to the images (Hysell, 1996). The time evolution of the scattering medium is moreover revealed by comparing images from successive integration times.

Four separate receivers are sampled simultaneously by the $30 \mathrm{MHz}$ radar data acquisition system. By using time division multiplexing, it was possible to record signals from five groups of receiving antennas with them. The positions of the five antenna modules in question are shown in Fig. 2. (Note that the two modules in the upper right corner of the figure are also used for transmission.) While the distribution of the modules might seem haphazard, the nine nonzero interferometry baselines that can be formed from them are nonredundant and distributed quasi-uniformly, as the lower panel of Fig. 2 illustrates.

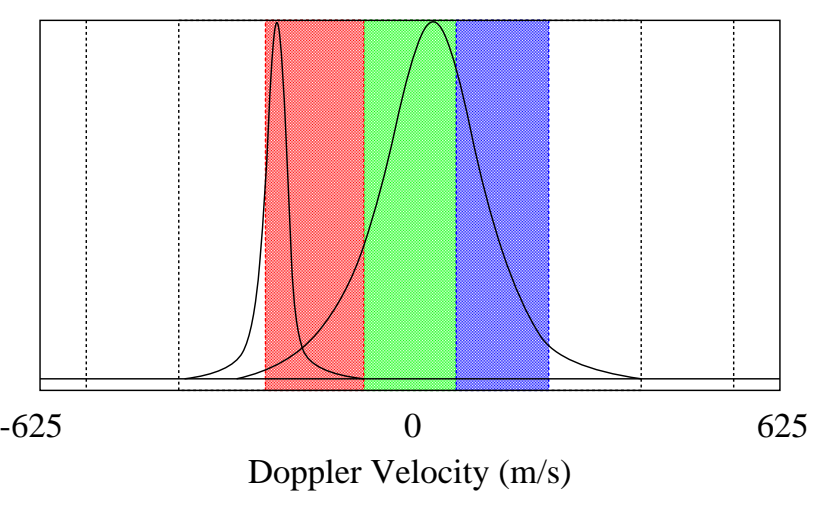

Fig. 3. Depiction of the parsing of the Doppler spectrum into 8 bins. Idealized type I (narrow) and type II (wide) Doppler spectra are shown for reference. Three separate images representing the signalto-noise ratio in the three lowest frequency bins are constructed. These are color-coded blue (for blue-shifted echoes), green, and red (for red-shifted echoes) and superimposed to create the final image.

The Nyquist velocity for our $30 \mathrm{MHz}$ observations is $\pm 625 \mathrm{~m} / \mathrm{s}$. The data are spectrally decomposed into 8 frequency bins during coherent processing, and three separate images are computed from the data in the three lowest frequency bins (see Fig. 3). These images are color coded and added to produce the final image. In this way, the brightness, hue, and saturation of the final image are indicative of the total scattered power, Doppler shift, and Doppler width of the echo. Red and blue shifted echoes will appear red and blue, respectively. Narrow type I (broad type II) spectra will give rise to pure (pastel) colors in the images. Consequently, each pixel in the images conveys information about the spectrum of the backscatter arising from the given range and bearing.

\section{Observations}

Figures 4 and 5 show electron densities vs. altitude measured by the Arecibo linefeed and Gregorian systems, respectively. The densities, which have been normalized using the Arecibo ionosonde, are plotted in units of $\mathrm{cm}^{13}$ on a logarithmic scale. The zenith angle for the two feeds was $15^{\circ}$, and the azimuths are plotted below the density data. The physical locations probed by the two feed systems were approximately $50 \mathrm{~km}$ apart at an altitude of $100 \mathrm{~km}$. Local sunset was at 19:04 LT, and most of the E-region can be seen to have recombined by about 19:20 LT. While the timing of various features differs somewhat between the two figures, the characteristics are similar. These include a thin sporadic E-layer at about $105 \mathrm{~km}$ altitude that, about an hour after sunset, suddenly became patchy and irregular. The layer descended to about $100 \mathrm{~km}$ between 21:00 and 22:00 LT, at which time it became more diffuse. A second faint layer was present at about 92 $94 \mathrm{~km}$ altitude, and a third layer seems to have appeared at about $95 \mathrm{~km}$ at 21:00 LT. After 23:00 LT, the layer was very thick, low, and increasingly diffuse. 

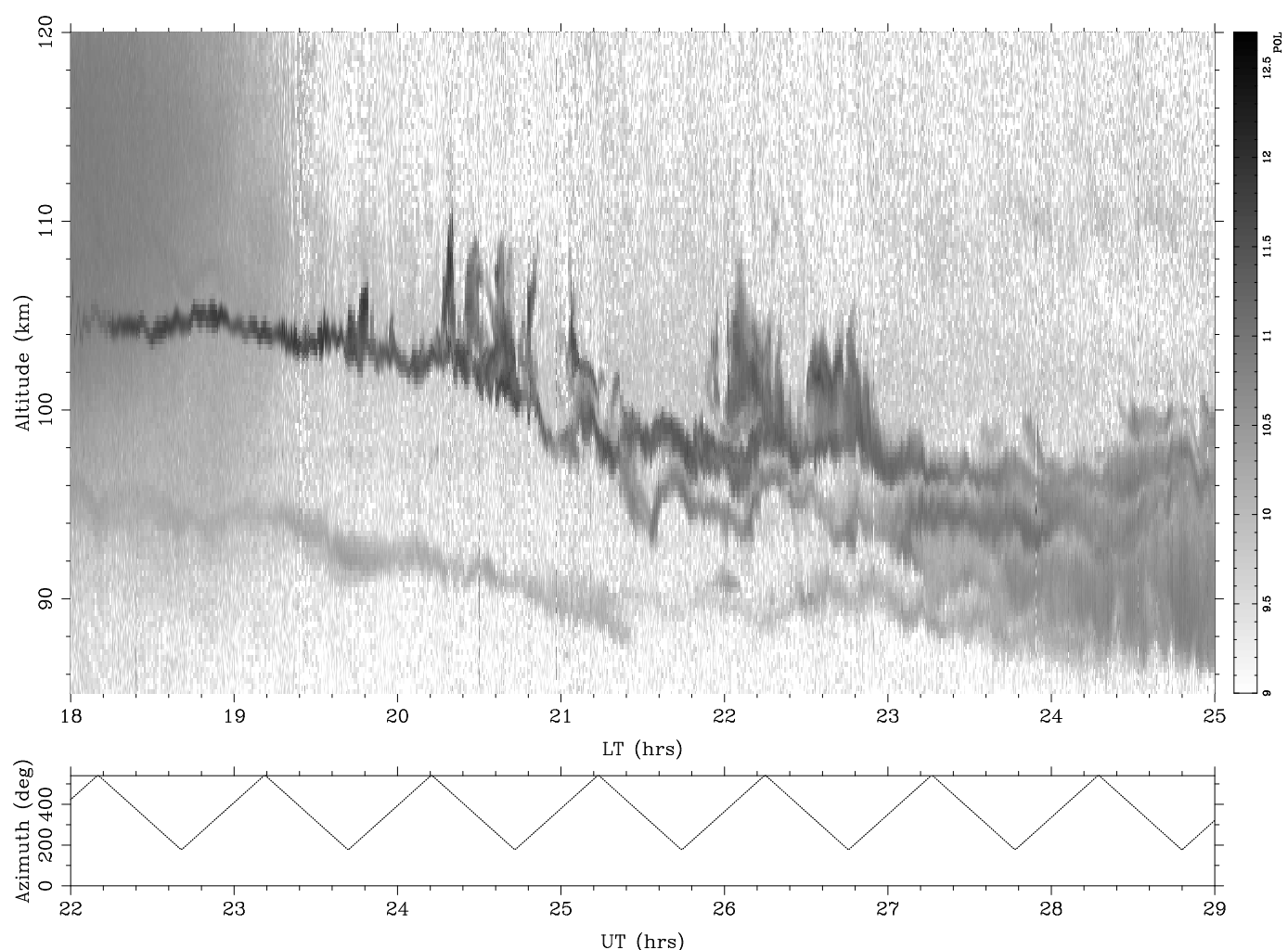

Fig. 4. Electron densities measured with the Arecibo linefeed antenna.
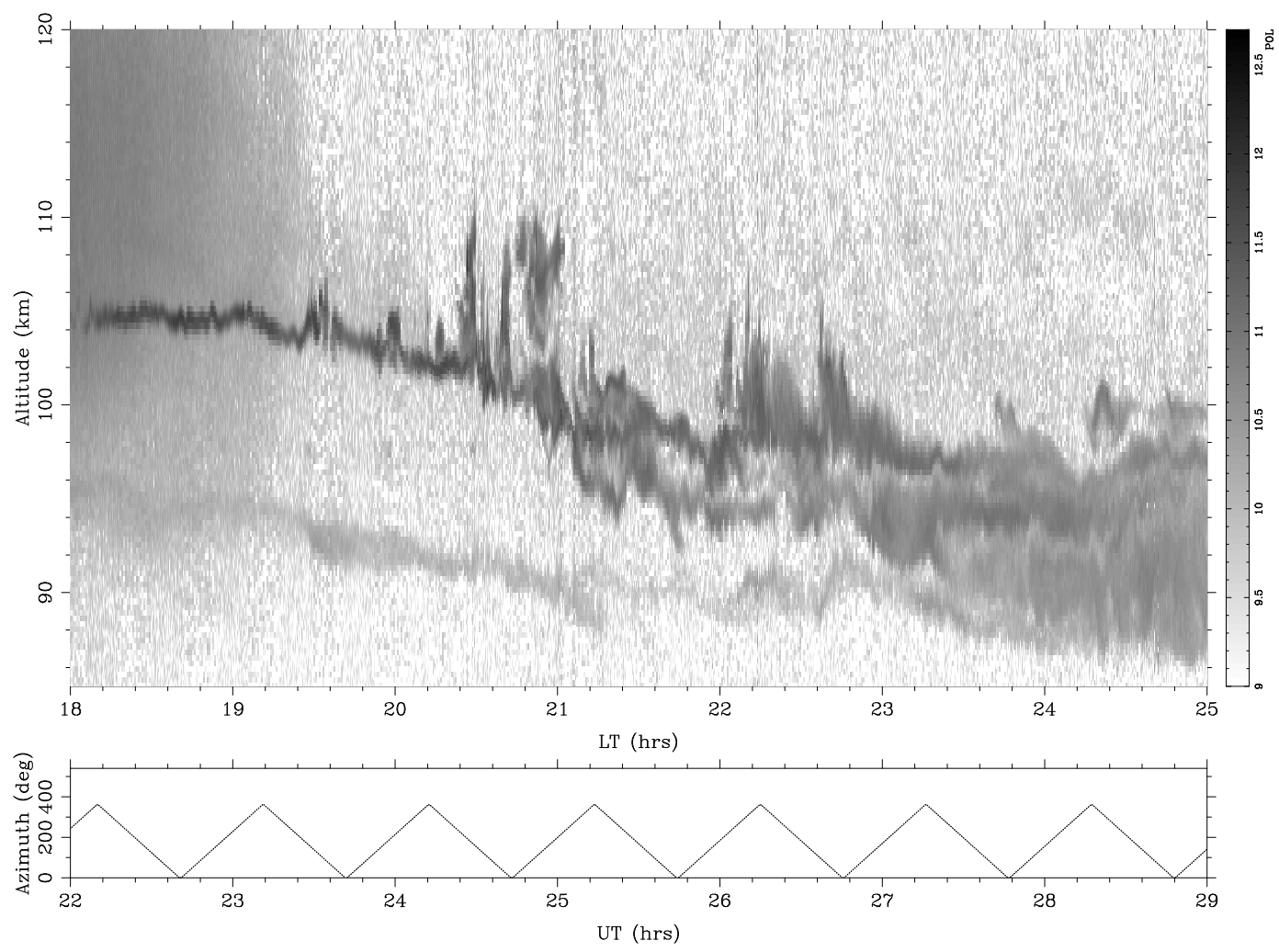

Fig. 5. Electron densities measured with the Arecibo Gregorian antenna. 


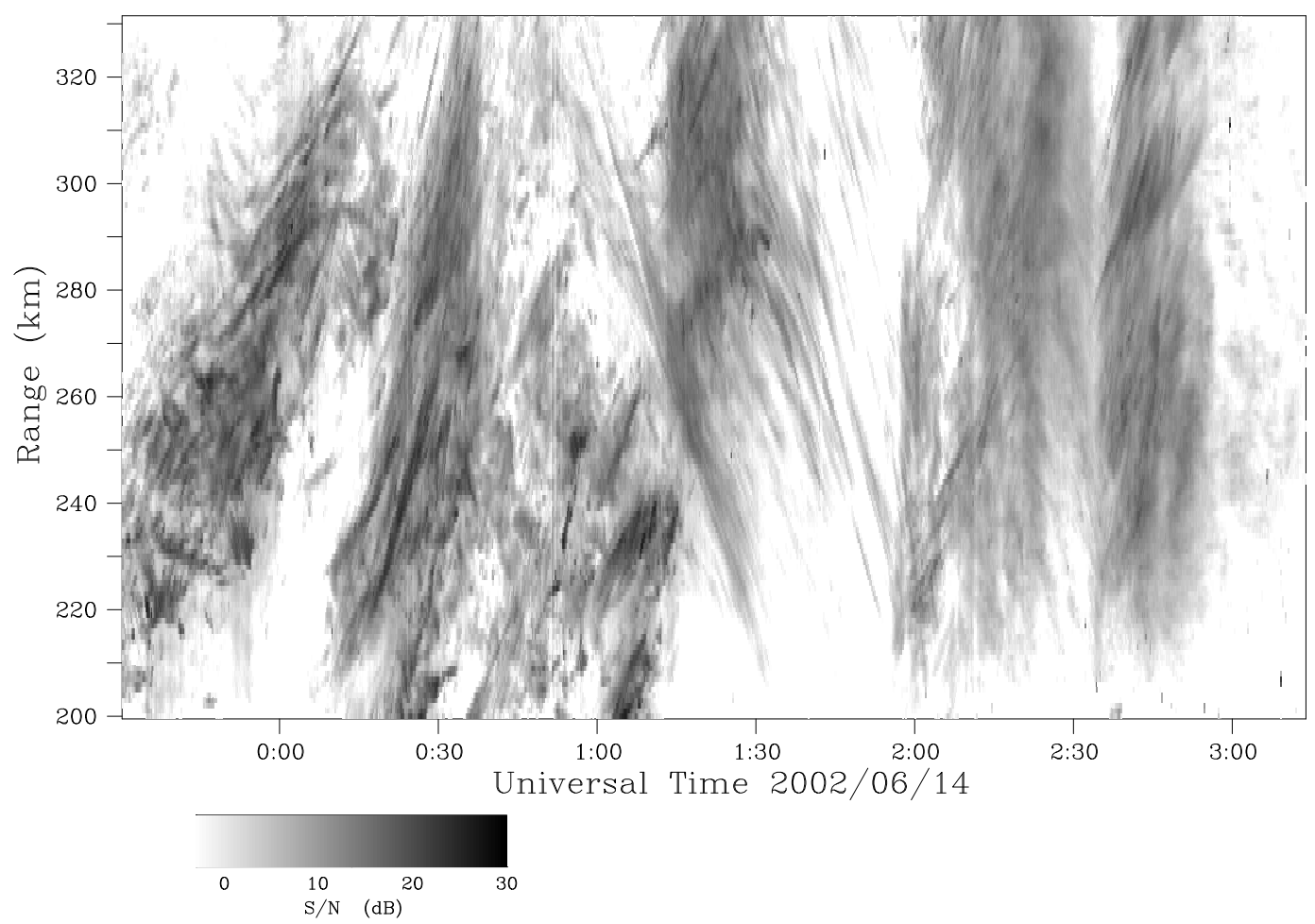

Fig. 6. Range-time-intensity plot of coherent echoes received by the $30 \mathrm{MHz}$ radar. Gray scales depict signal-to-noise ratio in dB. Note that $\mathrm{UT}=\mathrm{LT}+4 \mathrm{~h}$.

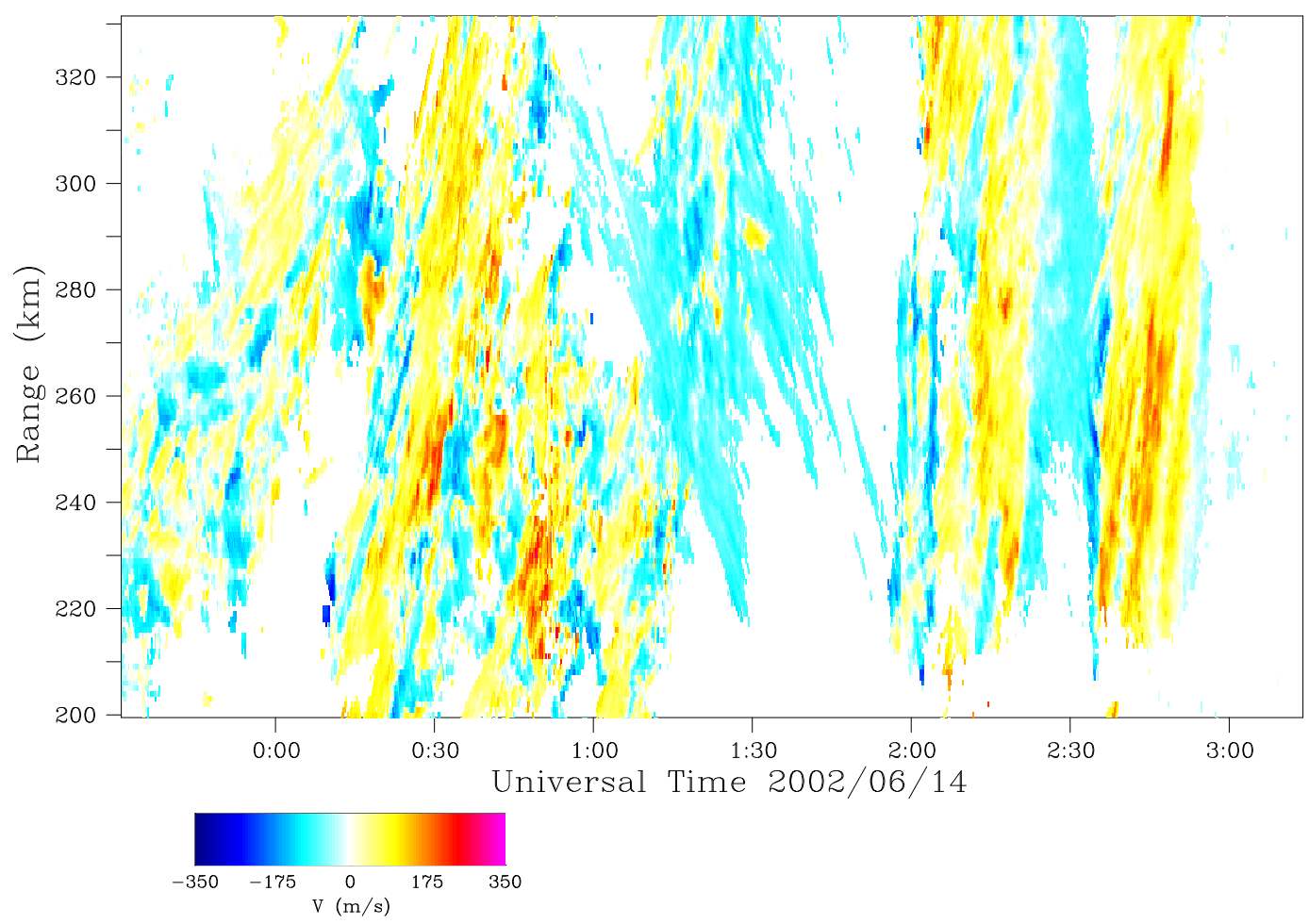

Fig. 7. First-moment Doppler velocities measured by the $30 \mathrm{MHz}$ radar. Positive Doppler velocities are color-coded blue and imply motion toward the radar. 
While multiple layers are evident in the figures at times, prior to 21:00 LT, the scene was dominated by a single, strong narrow layer between $100-110 \mathrm{~km}$ with only a very weak layer beneath it at the base of the E-region. It is unlikely that the latter had a significant effect on the electrodynamics of the E-region, given its low density and altitude. The stronger layer appears to be neither tilted nor deeply modulated. If it were, regular variations in its altitude would accompany and be synchronized with the azimuth scan, and the altitudes measured with the two feed systems would be markedly different. Moreover, there is no significant E-region ionization above the layer. Theories of irregularity generation that rely on multiple layers, tilted layers, deeply modulated layers, and density perturbations high in the E-regions, therefore, would not predict instability in these layers. However, we will show that intense meter-scale irregularities were present in the layers which became unstable shortly after sunset. The QP echoes received by the coherent scatter radar were as intense as any ever received. Whatever ingredients are necessary for instability were obviously present by 19:30 LT.

Beginning shortly after sunset, the layer broke into patches or plasma clouds similar to those reported by Miller and Smith (1975) and Smith and Miller (1980) and recently by Swartz et al. (2002). The clouds seen here are as dense or more than the sporadic E-layers surrounding them. Larsen (2000) hypothesized that these clouds may be the results of neutral Kelvin-Helmholtz instability driven by the shears thought to be responsible for forming the ionization layers in the first place. Quantifying a picture put forward by Haldoupis et al. (1996), Shalimov et al. (1998) and Hysell et al. (2002a) showed that such plasma clouds can produce strong polarization electric fields and currents, able to drive gradient drift and other plasma instabilities. Plasma clouds are the outstanding features in the Arecibo data and the focus of the present study.

A range time intensity representation of the coherent echoes received by the $30 \mathrm{MHz}$ radar on 14-15 June 2002 is given in Fig. 6. Most of the features in the plot could well be classified as quasi-periodic, particularly before 02:00 LT, and both positive and negative range rates (time rates of change of echo range) are apparent. There is a continuum of range rates, with the magnitude of the largest being about $70 \mathrm{~m} / \mathrm{s}$. The simultaneous occurrence of striations with positive and negative range rates (slopes) rules out any association of the striations with tilted sporadic E-layer configurations. In previous imaging radar studies of QP echoes, it was argued that the striations were telltale of the horizontal, wind-driven motion of discrete scattering structures drifting through the radar beam (Hysell et al., 2002b). Refraction (ray bending beginning at the edge of the plasma clouds) and the finite aspect sensitivity of the field-aligned irregularities make it possible for them to remain visible to the coherent scatter radar as they drift over significant distances. The maximum range extent possible in this scenario is greatest when the radar is looking in the zonal rather than the meridional direction, as the magnetic aspect angle changes most slowly with changing target bearing in that case. In the present experiments, the radar was looking nearly westward, and the QP echo striations are consequently comparatively long.

The first moment Doppler velocities of the coherent backscatter are illustrated in Fig. 7. Velocities as large as $\pm 250 \mathrm{~m} / \mathrm{s}$ are present in the data, although most of the measured velocities are less than about $\pm 100 \mathrm{~m} / \mathrm{s}$. There is some correspondence, although imperfect, between the range rate of the echoes and their Doppler shifts. Striations apparently moving toward and away from the radar generally have blue and red shifted Doppler spectra, respectively. However, there are many exceptions to the rule, and the magnitudes of the range rates and Doppler shifts seldom match. We surmise that the proper motion of the scattering regions underlying the striations contributes to the Doppler shift but that the polarization electric fields fixed to each one dominates the spectral shift.

Several of the fastest Doppler shifts seen in Fig. 7 are in fact telltale of type I echoes and modified two-stream instabilities (Farley, 1963). Figure 8 shows Doppler spectra for one such region between $220-231 \mathrm{~km}$ range and 00:10:30 00:11:43 UT. In this region, we see a preponderance of narrow spectra with positive Doppler shifts near $250 \mathrm{~m} / \mathrm{s}$. Other regions exhibit type I echoes with comparable but negative Doppler shifts. Spectra like these indicate that the polarization electric field in the scattering regions became large enough in several instances to exceed the threshold condition for the Farley-Buneman instability. This condition can be met within E-region plasma clouds with high metallic content in a background electric field, coupled to the F-region and elongated in the horizontal plane (Shalimov et al., 1998; Hysell et al., 2002a). Type I echoes were first observed at mid-latitudes by Haldoupis and Schlegel (1994) and have since been observed elsewhere during particularly intense sporadic E-layer events.

Figure 9 shows an in-beam radar image of the $30 \mathrm{MHz}$ coherent scatter recorded at sunset. Imaging has been used to determine echo power versus bearing in three dimensions. From range and bearing, we compute the latitude, longitude, and altitude. Altitude information is not depicted in this figure, however. The brightness, hue, and saturation of the colored regions indicate the signal-to-noise ratio, Doppler shift, and spectral width of the coherent echoes. Signal-to-noise ratios are plotted on a scale between 8 and $38 \mathrm{~dB}$ here.

The image in Fig. 9 depicts a number of discrete, localized, patchy scatterers. Over time, animations show that the patches drift mainly westward or southwestward, although some on the west side of the image drift eastward toward St. Croix. Each patch corresponds to a striation in the RTI diagram in Fig. 6, and the range rates of the striations correspond to their line-of-sight drifts with respect to St. Croix. Differences in the motions of the patches give the striations in Fig. 6 different slopes and even permit them to cross. This image is qualitatively similar to those presented by Hysell et al. (2002b), and we will again associate the patches in the images with drifting, polarized E-region clouds. Evidence of polarization is found in the circulation evident in the patches, 


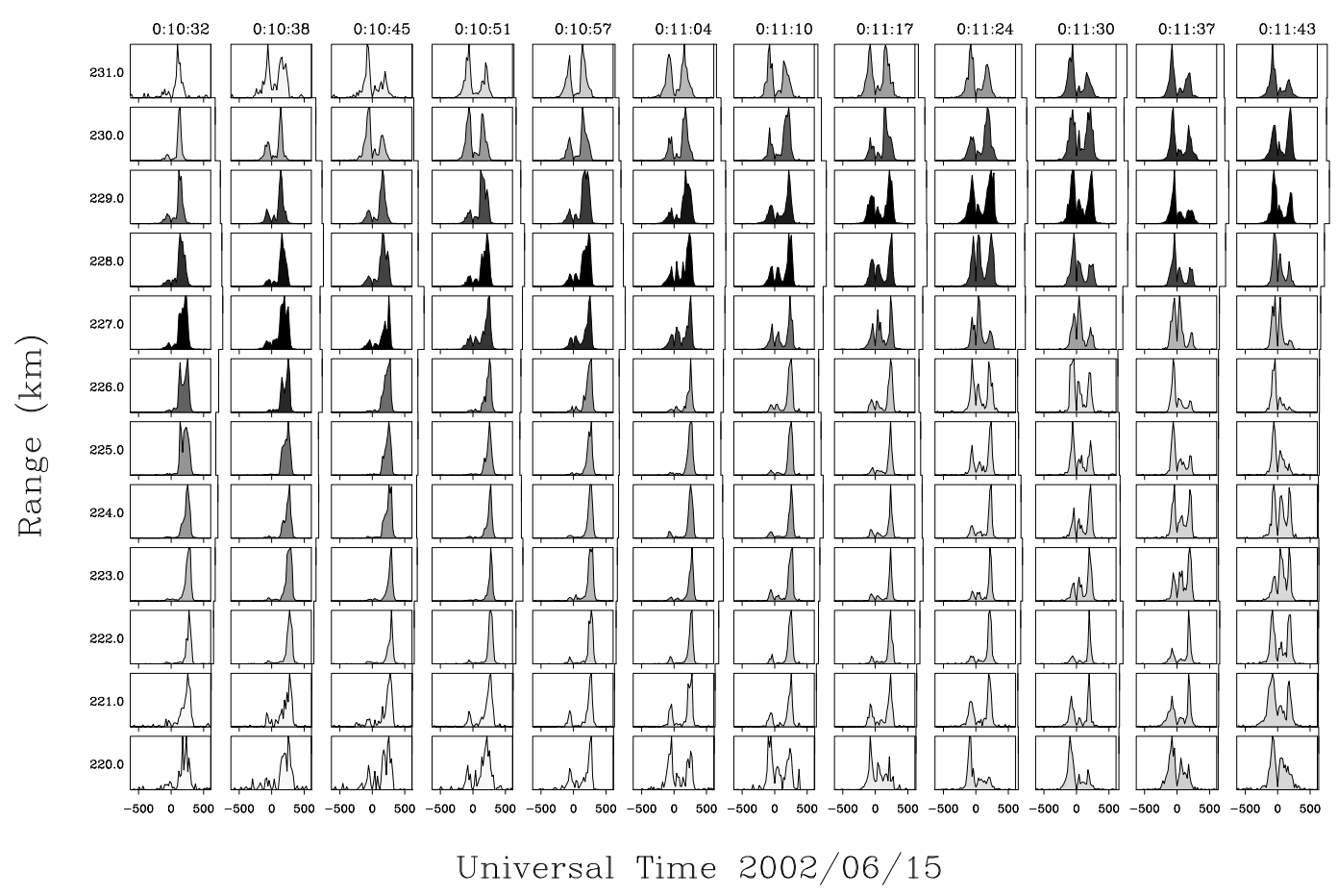

Fig. 8. Doppler spectra for echoes received between 220-231 km range, 00:10:32-00:11:43 UT. The narrow spectral forms with Doppler shifts close to $+250 \mathrm{~m} / \mathrm{s}$ are type I spectra, indicative of modified two-stream instabilities.

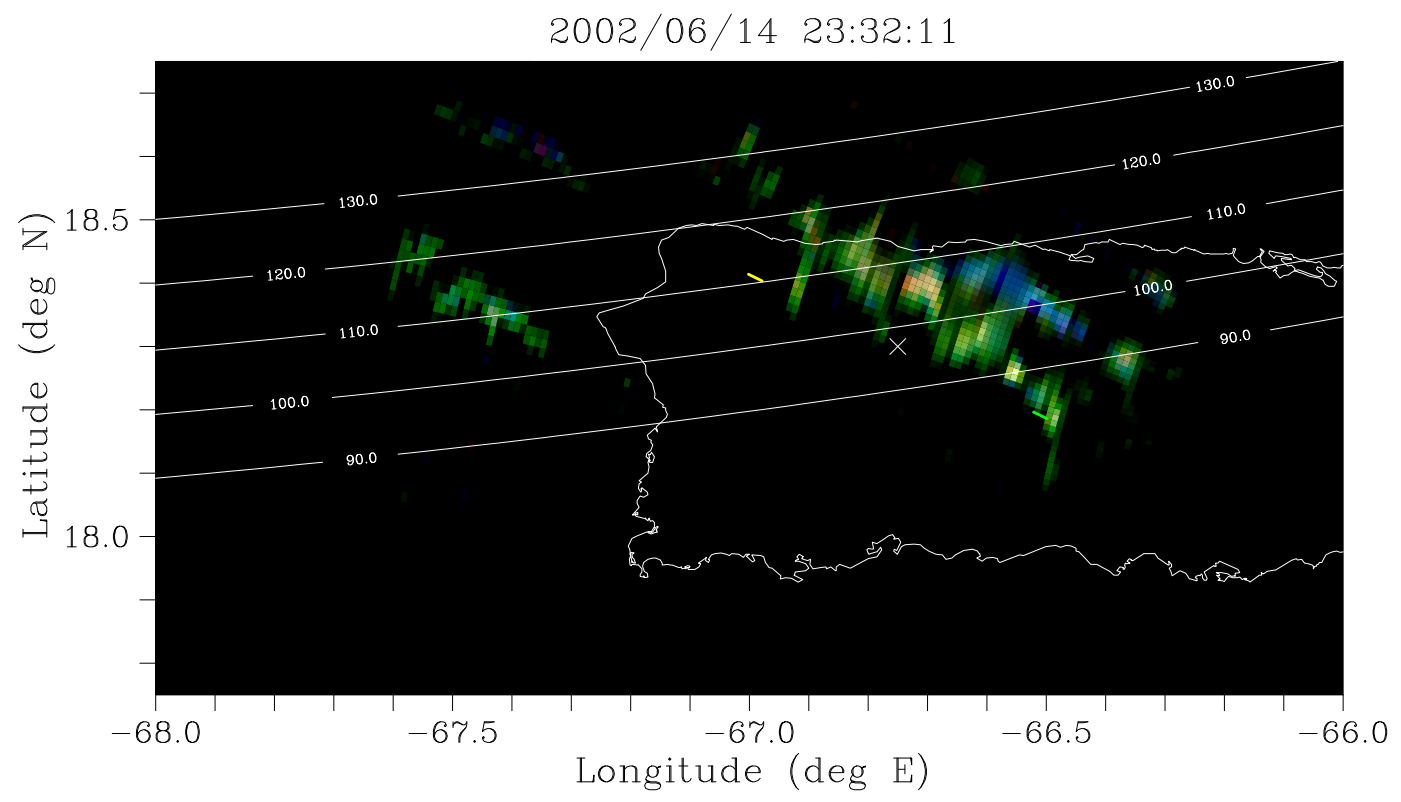

Fig. 9. Radar image of coherent echoes received at 23:32 UT. Note that UT=LT+4. 
where the hue (Doppler shift) is typically different in the center and at the periphery.

The " $\mathrm{X}$ " in the figure in Northwest Puerto Rico represents the location of the Arecibo radar. Yellow and green lines radiating from this point represent, respectively, the regions where the beams from the Arecibo linefeed and Gregorian antennas intercept the E-region between 100-110 km in altitude at the time indicated. Images like Fig. 9 make it possible to collocate sources of coherent scatter with the sporadic E-layer features responsible for them. Note, for instance, that in Fig. 9, the Gregorian beam intercepts a coherent scatter "bright spot", whereas the linefeed system does not. Consulting Figs. 4 and 5 reveals that both of the Arecibo beams were detecting sporadic E ionization layers at 23:30 LT (19:30 UT). However, the Gregorian beam passed through an irregular, moderately thick cloud of ionization at this moment, while the linefeed observed only a very thin layer. The first collision of the linefeed beam with a region of strong coherent scatter occurred at about 23:48 LT, at which time a thick, irregular cloud was observed with the linefeed. By animating sequences of images like Fig. 9, we were able to compare the entire incoherent and coherent scatter data sets for the June 14-15 event in this way. Overall, we can demonstrate a very high correspondence between the coherent backscatter patches and the ionization clouds (Hysell et al., 2003).

The altitude of the coherent scatter is depicted in Fig. 10. Here, we present the centroid altitude of the backscatter, the average altitude weighted by the backscatter intensity. For all of the patches in the vicinity of Arecibo, that altitude is approximately $105 \mathrm{~km}$. This agrees with the altitude of the sporadic E-layer and the plasma clouds in the incoherent scatter data. The figure does not always match the altitude of the locus of perpendicularity for field-aligned backscatter, however. Hysell et al. (2002b) showed that the restrictions for field-aligned VHF backscatter are relaxed in practice by the effects of refraction and by the finite aspect sensitivity of the irregularities, and that a discrepancy of several kilometers can easily exist for $30 \mathrm{MHz}$ and even $50 \mathrm{MHz}$ backscatter radars. The locus of perpendicularity, therefore, does not impose very strict restrictions on the bearing of coherent backscatter, as Fig. 9 demonstrates. True bearing can only be determined reliably with interferometry.

A remarkable feature of Fig. 9 is the tendency for the scattering patches to fall along lines which are somewhat close to, but generally not parallel to, the line-of-sight back to St. Croix. Similar linear formations of scatterers were observed with the MU and Clemson University radars, although the phenomenon was less discernible (Hysell et al., 2002b). Over Puerto Rico, however, the lines were more evident and prone to coalesce into multiple, unbroken, frontal structures propagating across the ionosphere.

Figure 11 illustrates an example of these structures or waves, which are more striking to the eye here than in data sets from imaging experiments conducted elsewhere. We regard the structures as waves, both because wavefronts are evident in the image brightness and because the observed
Doppler shifts also vary periodically between wavefronts. In Fig. 11, a large-scale wave with wavefronts running from northwest to southeast is shown. The wavelength is about $30 \mathrm{~km}$, and the period is about 10 minutes. Animated sequences of images confirm that the wave propagates to the southwest. Doppler shifts alternate from large positive to negative values. These are the line-of-sight phase speeds of the small-scale irregularities observed from St. Croix. We expect these phase speeds to be mainly indicative of polarization electric fields in the direction normal to both the radar line of sight and to the geomagnetic field, that is, northeastward and upward or southwestward and downward, approximately normal to the wavefronts in Fig. 11. The images suggest a large-scale electrostatic wave moving through the region.

At the time that the large-scale wave was passing over Puerto Rico, Arecibo observed a number of very thick and intense plasma irregularities or clouds with both of its feed systems. There is a high degree of correspondence between these clouds and the wavefronts in the coherent scatter radar images. It is when the yellow and green radial markers in the images pass through the brightest parts of the wavefronts that the corresponding Arecibo beam systems detect the clouds. As the wavefronts are very elongated, we surmise that the ionization clouds are either very elongated, or occur in long chains which move with the waves.

As the evening and the QP echo event progressed, the ionization irregularities detected by Arecibo became more diffuse, spreading in time and in altitude in the range-time plots shown above. The coherent backscatter in the radar images also became more diffuse, with the boundaries between the phases of the large-scale waves blending in such a way that scatter was received over very large, continuous regions of space. An example is shown in Fig. 12. Here, the backscatter intensity is essentially constant over the region where the scatter originates. The streaks in the RTI diagram (Fig. 6) are consequently difficult to isolate and distinguish. Still evident in the radar images is the large-scale wave. Between 23:30 and 02:15 UT, the propagation direction of the wave appears to have rotated from southwest to nearly southward.

Finally, Fig. 13 shows the centroid altitudes of the coherent backscatter from the previous radar image. The range of altitudes shown spans about $95-110 \mathrm{~km}$ in the vicinity of Arecibo and agrees well with the altitude range of the sporadic E-layer at this time. There is also a gradual tilt in the centroid altitudes, with altitude decreasing gradually from west to east. The tilt is modest in the vicinity of Arecibo, and it is unclear from the incoherent scatter data whether the underlying sporadic E-layer is also tilted. Figure 13 is meant to illustrate that no deep modulation in the layer is associated with the wavefronts so visible in the brightness and Doppler data. Instead, all of the coherent backscatter arrives from altitudes that vary only gradually over the radar illuminated volume, at least in the vicinity of Arecibo. Also, we reiterate that the locus of perpendicularity does not constrain the scattering geometry rigidly and gives only a rough estimate of the altitude of the coherent backscatter. In practice, backscatter 

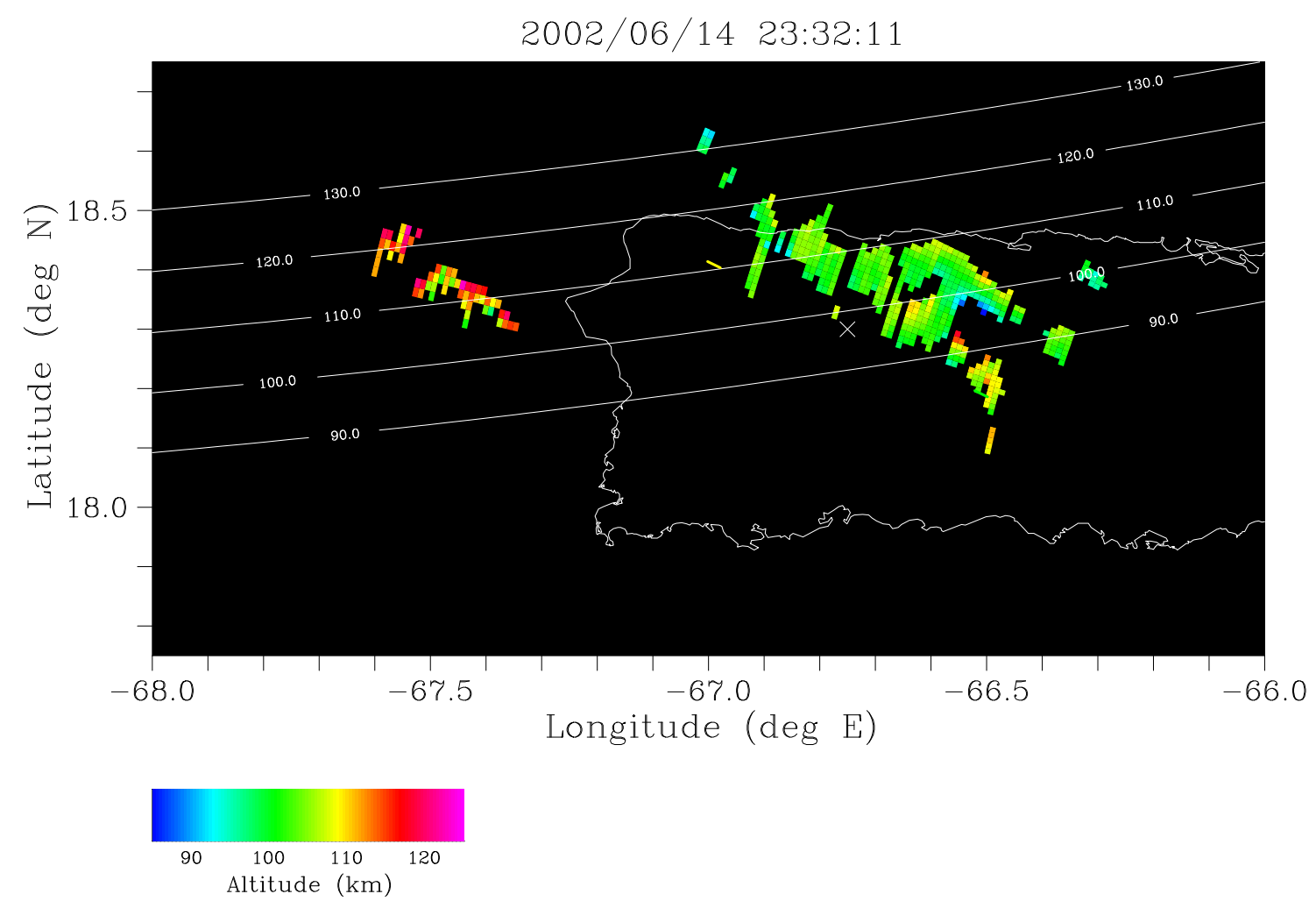

Fig. 10. False-color representation of the centroid altitude of the backscatter shown in the previous figure.

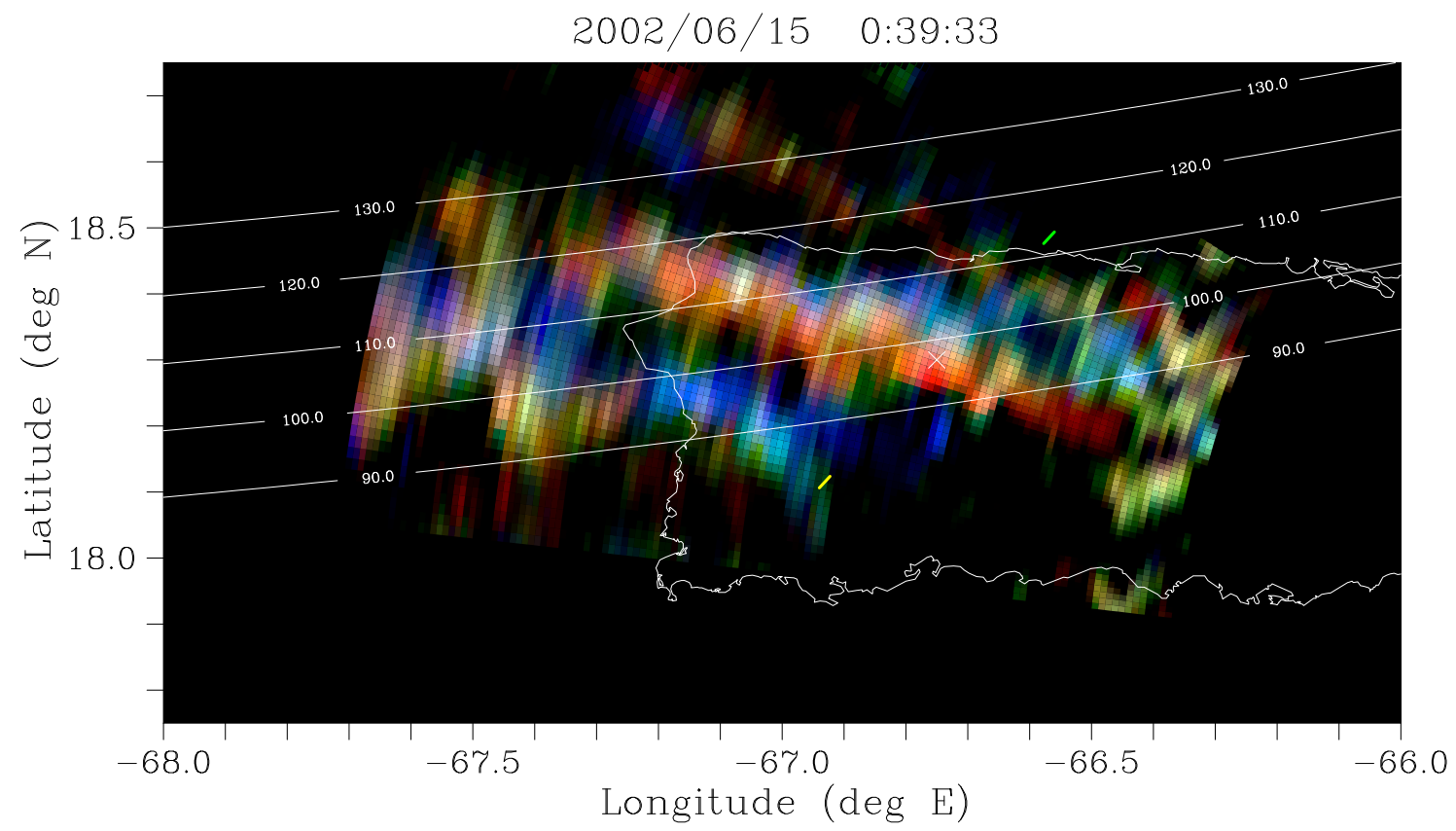

Fig. 11. Radar image of coherent echoes received at 00:39 UT. 


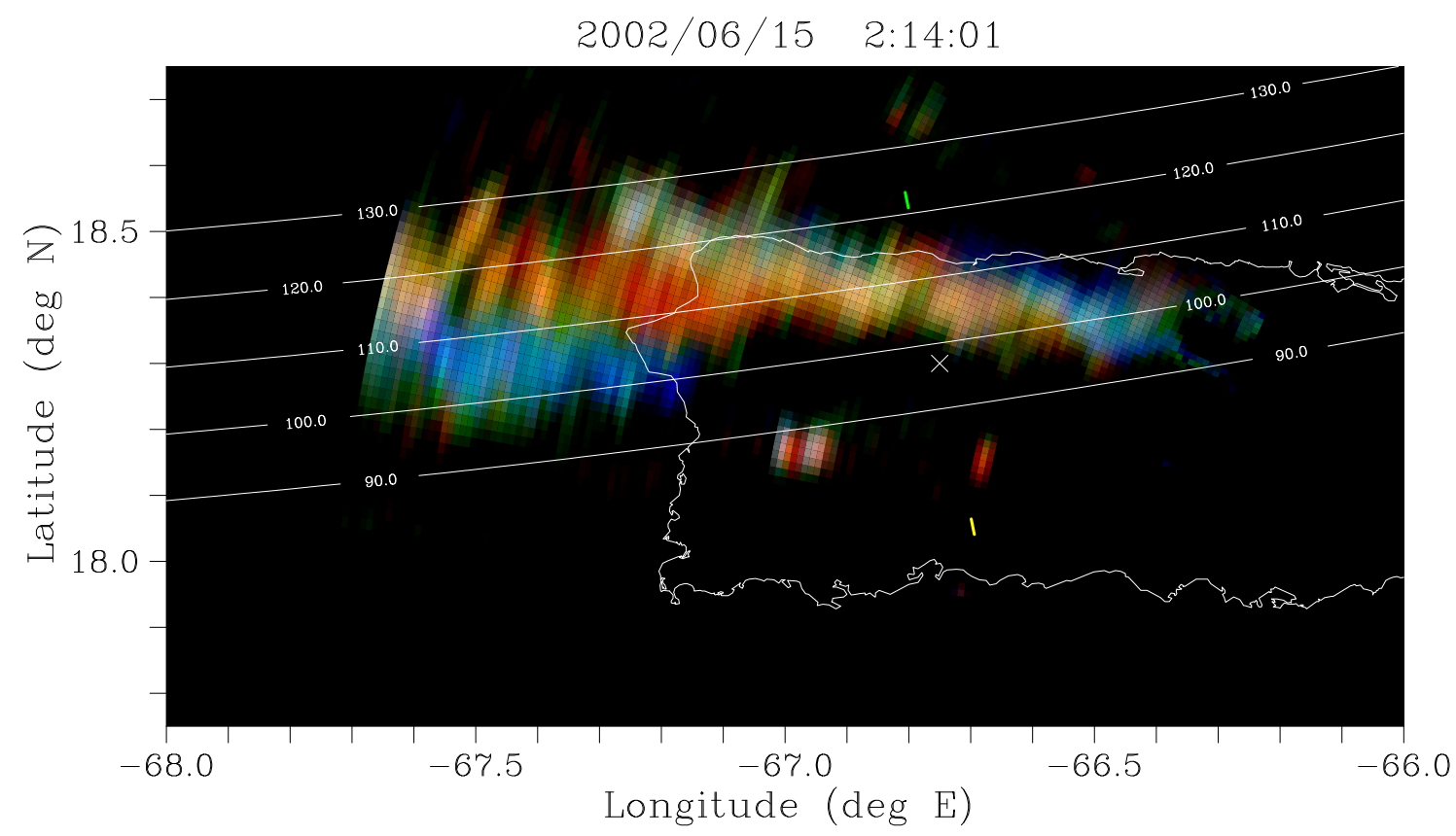

Fig. 12. Radar image of coherent echoes received at 02:14 UT.
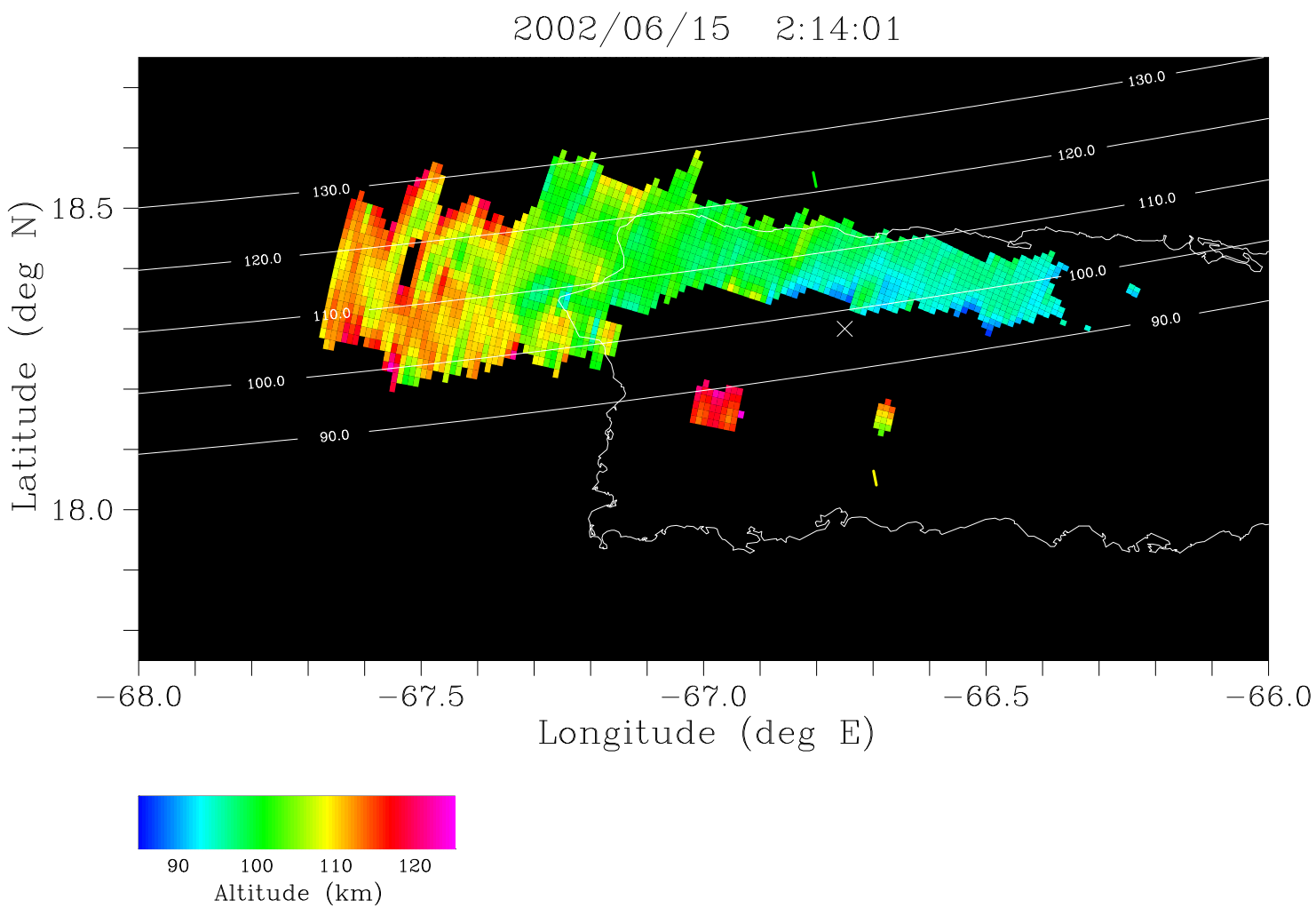

Fig. 13. Representation of the centroid altitude of the backscatter shown in the previous figure. 
can come from altitudes several $\mathrm{km}$ above and below the locus of perpendicularity.

\section{Summary and discussion}

The objective of this investigation was to match the fieldaligned irregularities responsible for QP echoes with underlying features in sporadic $\mathrm{E}$ ionization layers. Common volume radar observations were made in the Caribbean using the Arecibo incoherent scatter radar and a portable, imaging coherent scatter radar located on St. Croix. A prototypical QP echo event occurred on 14-15 June 2002, just after Eregion sunset. Prior to about 20:00 LT, this event appeared from the point of view of the imaging radar to be similar to others observed from Clemson, South Carolina and with the MU radar in Japan (Hysell et al., 2002b). A number of localized, patchy scattering regions appeared and drifted through the radar illuminated volume, causing telltale striations in the RTI power map. These regions occupied a narrow range of altitudes close to $105 \mathrm{~km}$ and maintained altitude as they drifted. Drifts were mainly southwestward but varied in space and time. The Doppler shifts varied across the scattering regions as well, indicating circulation patterns suggestive of electric dipole cells. The polarization electric fields were sometimes large enough to exceed the threshold condition for Farley-Buneman instabilities, as indicated by the detection of type 1 echoes.

While the QP echoes were being received, incoherent scatter data from Arecibo indicated that the salient feature of the ionosphere was the presence of irregular, dense clouds of ionization extending above a narrow, flat sporadic E-layer. The physical locations of the clouds corresponded closely in three dimensions to the locations from which coherent backscatter was received. Therefore, we assert that unstable, patchy sporadic E-layers drifting through the radar illuminated volume are the source of QP echoes.

After about 20:00 LT, the patchy scatterers became distributed along bands or fronts aligned normal to the apparent direction of motion. The patches ultimately coalesced to form distinctive wavefronts. Both the intensity and the Doppler shifts of the coherent backscatter varied periodically across the wavefronts. The strongest backscatter and largest electric fields of the evening were observed at this time. Also at this time, Arecibo detected very distinct and dense clouds of ionization at altitudes between 100 and $110 \mathrm{~km}$ with densities approaching $10^{6} \mathrm{~cm}^{-3}$. The locations of the clouds corresponded closely to the regions of most intense coherent backscatter. The clouds were as dense or more dense than the sporadic E-layers surrounding them.

After 22:00 LT, the backscatter became more diffuse and filled in the regions between the wavefronts, which nevertheless maintained their characteristic periodic Doppler signatures. Backscatter was received from a large fraction of the sector illuminated by the coherent scatter radar. Throughout this time, the sporadic E-layers seen by Arecibo were spreading in altitude and gradually descending.
The large-scale electrostatic waves identified by these experiments represent a previously undetected aspect of midlatitude sporadic E-layers. While long frontal bands of coherent backscatter were detected from time to time in imaging experiments conducted with the MU and Clemson radars, those were not nearly so common, distinct, or persistent as the large-scale waves documented here, and the wave-like variations in the Doppler shifts, in particular, have not been observed before. Meanwhile, large-scale waves such as these were observed on several occasions during the summer 2002 experiments from St. Croix and appeared to be more the rule than the exception.

One factor that might explain why large-scale waves have been detected from St. Croix but not from other radar sites involves the viewing geometry of our Caribbean experiments. In order to share a common volume with Arecibo, the main beam of the coherent scatter radar was directed west north-westward from St. Croix in a direction that turned out to be at least at times, something similar to parallel with the wavefronts of the large-scale waves. Since the electric fields in the large-scale electrostatic waves must be normal to the wavefronts, the associated $\mathbf{E} \times \mathbf{B}$ drifts must be parallel to them and, therefore, in the coherent scatter radar line-of-sight. Consequently, they could be detected readily in the Doppler shifts of the coherent echoes. In previous radar imaging experiments, the radar line-of-sight was always approximately northward. Even if southward or southwestward propagating large-scale electrostatic waves were present during those experiments, their electric field signatures would have been difficult to detect in the coherent scatter Doppler spectra. Without those signatures, the waves themselves would have been hard to discern in much of the data recorded in the Caribbean, particularly those from after 22:00 LT. Certainly, there is no suggestion of large-scale waves in the RTI plot in Fig. 6. Doppler-resolved in-beam radar imaging is required to detect this phenomenon and is most sensitive to it when the radar line of sight is directed west north-westward.

At present, the cause of the large-scale waves is unknown. The structure that is evident in Fig. 11 represents the strength and location of the small-scale plasma waves responsible for the coherent scatter detected with the radar and are not tracers of the neutral motion or neutral dynamical structure. The organization that is evident in the scatterers, however, is similar to that which would be expected in a shear instability once it is fully developed. Fritts et al. $(1993,1994)$ have modeled and discussed the dynamics of such fully three-dimensional instabilities in which secondary instabilities with wave-numbers 2 to 5 times that of the primary instability wave-number develop in the flow oriented at $90^{\circ}$ to the primary wave fronts. Figure 11, in particular, suggests a similar organization in the coherent backscatter structure, with a primary wavelength of approximately $30 \mathrm{~km}$ and a secondary wavelength of $15 \mathrm{~km}$ or less. The wavefronts are especially clear in the region between 66.9 and $67.4^{\circ} \mathrm{W}$ and and between 18.1 and $18.4^{\circ} \mathrm{N}$. Larsen (2000) discussed the evidence for the link between shear instabilities in the lower 
E-region and the occurrence of QP echoes, and suggested that the Kelvin-Helmholtz billows could provide the initial vertical displacements that lead to the plasma instabilities which result in the backscatter detected with the radar. In that case, the larger scale structure is expected to retain the signatures of the neutral shear instabilities that initiate the plasma instabilities. The measurements from 14-15 June appear to be consistent with that scenario. The primary wavelength of $30 \mathrm{~km}$ is also very close to the value for the horizontal separation between adjacent billows predicted by Larsen (2000) based on typical shear instability layer depths observed with chemical tracer releases during sporadic E-events.

We note that, although the existence of shear instability structure has been surmised from the characteristics and movement of QP echoes and from supplementary wind measurements, when available, the detailed imaging analysis, of the type applied here to the June 14-15 data, reveals, for the first time, the details in the structure within the scattering volume.

The $30 \mathrm{~km}$ wavelength is very long compared to any scale sizes related to E-region plasma instabilities and is long enough to ensure efficient electrostatic coupling along magnetic field lines between the E- and F-region. The mechanism for generating large polarization electric fields in elongated E-region plasma structures described by Shalimov et al. (1998) and by Hysell et al. (2002a) is ineffective at these scale sizes. Moreover, it is unclear why the large-scale electric fields were not shorted out in the F-region, which should have dominated the integrated conductivity on the affected flux tubes. We may hypothesize that an F-region traveling ionospheric disturbance (TID), such as those commonly observed over Japan with the GEONET GPS network (Saito et al., 1998, 2001) or with all-sky airglow imagers (Shiokawa et al., 2003a, b), may have been present during the QP echo observations. Electrostatic waves generated in the E-region could then have survived in flux tubes in the conductivity troughs associated with the TID. The 60-90-min characteristic period of the TID might explain the common tendency for QP echoes to appear in clusters or groupings spaced by such intervals. Indeed, the QP echoes in Fig. 6 occurred in four distinct clusters separated by approximately one hour. On flux tubes where the F-region conductivity is supressed, large E-region polarization electric fields can arise in response to E-region conductivity gradients over a broad range of scale sizes. The amplitude of the polarization electric fields will be controlled by the ratio of the plasma density inside and outside the sporadic E-layer patches, a potentially very large ratio in view of the Arecibo data presented earlier. In order to evaluate this hypothesis and to identify the cause of the sporadic E-layer structuring at the root of QP echoes, repeated common-volume radar experiments with more exhaustive F-region and lower thermospheric diagnostics will be necessary.

Acknowledgements. DLH is indebted to Major Stout and the personnel of the Virgin Islands Army National Guard Armory, St. Croix USVI, for their hospitality and assistance during our experi- ments and also to S. Nicholson, R. Bishop, J. M. Velez, and J. M. Rosado Roman for their support in the field. This work was supported by NSF grants no. ATM-0003168 to Clemson University and ATM-0225686 to Cornell University. The Arecibo observatory is a major facility of the National Astronomy and Ionosphere Center which is operated by Cornell University under a cooperative agreement with the National Science Foundation.

Topical editor M. Lester thanks C. Haldoupis and another referee for their help in evaluating this paper.

\section{References}

Ables, J. G.: Maximum entropy spectral analysis, Astron. Astrophys. Suppl. Ser., 15, 383, 1974.

Farley, D. T.: A plasma instability resulting in field-aligned irregularities in the ionosphere, J. Geophys. Res., 68, 6083, 1963.

Farley, D. T., Ierkic, H. M., and Fejer, B. G.: Radar interferometry: A new technique for studying plasma turbulence in the ionosphere, J. Geophys. Res., 86, 1467, 1981.

Fritts, D. C., Isler, J. R., and Thomas, G. E.: Wave breaking signatures in noctilucent clouds, Geophys. Res. Lett., 20, 2039, 1993.

Fritts, D. C., Isler, J. R., and Andreassen, O.: Gravity wave breaking in two and three dimensions, 2 . Three-dimensional evolution and instability structure, J. Geophys. Res., 99, 8109, 1994.

Haldoupis, C. and Schlegel, K.: Observation of the modified two-stream plasma instability in the mid-latitude E-region ionosphere, J. Geophys. Res., 99, 6219, 1994.

Haldoupis, C., Schlegel, K., and Farley, D. T.: An explanation for type 1 radar echoes from the mid-latitude E-region ionosphere, Geophys. Res. Lett., 23, 97, 1996.

Hysell, D. L.: Radar imaging of equatorial F-region irregularities with maximum entropy interferometry, Radio Sci., 31, 1567, 1996.

Hysell, D. L., Yamamoto, M., and Fukao, S.: Simulations of plasma clouds in the mid-latitude E-region ionosphere with implications for type I and type II quasi-periodic echoes, J. Geophys. Res., 107, 1313, 2002a.

Hysell, D. L., Yamamoto, M., and Fukao, S.: Imaging radar observations and theory of type I and type II quasi-periodic echoes, J. Geophys. Res., 107, 1360, 2002b.

Hysell, D. L., Larsen, M. F., and Zhou, Q. H.: Radar imaging of E-region plasma irregularities over Arecibo, Paper presented at the EGS-AGU-EGU Joint Assembly, Nice, France, April 6-11, 2003.

Jaynes, E. T.: On the rationale of maximum-entropy methods, Proc. IEEE, 70, 939, 1982.

Kudeki, E. and Sürücü, F.: Radar interferometric imaging of fieldaligned plasma irregularities in the equatorial electrojet, Geophys. Res. Lett., 18, 41, 1991.

Larsen, M. F.: A shear instability seeding mechanism for quasiperiodic radar echoes, J. Geophys. Res., 105, 24 931, 2000.

Maruyama, T., Fukao, S., and Yamamoto, M.: A possible mechanism for echo-striation generation of radar backscatter from midlatitude sporadic $E$, Radio Sci., 35, 1155, 2000.

Miller, K. L. and Smith, L. G.: Horizontal structure of mid-latitude sporadic E-layers observed by incoherent scatter radar, Radio Sci., 10, 271, 1975.

Ogawa, T., Takahashi, O., Otsuka, Y., Nozaki, K., Yamamoto, M., and Kita, K.: Simultaneous MU radar and ionospheric sounder observations of mid-latitude E-region irregularities and sporadic E-layer, J. Geophys. Res., 107, 1275, 2002. 
Saito, A., Fukao, S., and Miyazaki, S.: High resolution mapping of TEC perturbations with the GSI GPS netwark over Japan, Geophys. Res. Lett., 25, 3079, 1998.

Saito, A., Nishimura, M., Yamamoto, M., Kutoba, K., Shiokawa, K., Otsuka, Y., Tsugawa, T., Fukao, S., Ogawa, T., Ishii, M., Sakanoi, T., and Miyazaki, S.: Traveling ionospheric disturbances detected in the FRONT campaign, Geophys. Res. Lett., 28, 689, 2001.

Seyler, C. E., Rosado-Roman, J. M., and Farley, D. T.: A nonlocal theory of the gradient-drift instability in ionospheric plasmas at mid-latitudes, J. Atmos. Sol. Terr. Phys., in press, 2004.

Shalimov, S., Haldoupis, C., and Schlegel, K.: Large polarization electric fields associated with mid-latitude sporadic $E$, J. Geophys. Res., 103, $11617,1998$.

Shiokawa, K., Ihara, C., Otsuka, Y., and Ogawa, T.: Statistical study of nighttime medium-scale traveling ionospheric disturbances using mid-latitude airglow images, J. Geophys. Res., 108, 1052, 2003a.

Shiokawa, K., Otsuka, Y., Ihara, C., Ogawa, T., and Rich, F. J.: Ground and satellite observations of nighttime medium-scale traveling ionospheric disturbance at mid-latitude, J. Geophys. Res., 108, 1145, 2003b.

Smith, L. G. and Miller, K. L.: Sporadic layers and unstable wind shears, J. Atmos. Terr. Phys., 42, 45, 1980.

Sulzer, M. P.: A phase modulation technique for a sevenfold statistical improvement in incoherent scatter data-taking, Radio Sci., 21, 737, 1986.

Swartz, W. E., Collins, S. C., Kelley, M. C., Makela, J. J., Kudeki, E., Franke, S., Urbina, J., Aponte, N., Gonzalez, S., Sulzer, M. P., and Friedman, J. S.: First observations of an F-region turbulent upwelling coincident with severe E-region plasma and neutral atmospheric perturbations, J. Atmos. Sol. Terr. Phys., 64, 1545, 2002.

Thompson, A. R.: Interferometry and Synthesis in Radio Astronomy, edited by John Wiley, New York, 1986.

Tsunoda, R. T., Fukao, S., and Yamamoto, M.: On the origin of quasi-periodic backscatter from sporadic $E$, Radio Sci., 29, 349, 1994.

Whitehead, J. D.: Recent work on mid-latitude and equatorial sporadic E, J. Atmos. Terr. Phys., 51, 401, 1989.

Wilczek, R. and Drapatz, S.: A high accuracy algorithm for maximum entropy image restoration in the case of small data sets, Astron. Astrophys., 142, 9, 1985.

Woodman, R. F.: Coherent radar imaging: Signal processing and statistical properties, Radio Sci., 32, 2373, 1997.

Woodman, R. F., Yamamoto, M., and Fukao, S.: Gravity wave modulation of gradient drift instabilities in mid-latitude sporadic $E$ irregularities, Geophys. Res. Lett., 18, 1197, 1991.

Yamamoto, M., Fukao, S., Woodman, R. F., Ogawa, T., Tsuda, T., and Kato, K.: Mid-latitude E-region field-aligned irregularities observed with the MU radar, J. Geophys. Res., 96, 15 943, 1991.

Yamamoto, M., Fukao, S., Ogawa, T., Tsuda, T., and Kato, S.: A morphological study of mid-latitude E-region field-aligned irregularities observed with the MU radar, J. Atmos. Terr. Phys., 54, 769, 1992.

Yokoyama, T., Yamamoto, M., and Fukao, S.: Computer simulation of polarization electric fields as a source of mid-latitude fieldaligned irregularities, J. Geophys. Res., 108, 1054, 2003. 